\title{
Implementing Gamification on a Web-Based Recruitment System using Marczewski's Gamification Framework: An Overview
}

\author{
Michael Shane ${ }^{1}$, Lukman Wisnudrajat ${ }^{2}$, Gunawan Wang ${ }^{3}$, Emil Robert Kaburuan ${ }^{4}$ \\ 1,2,3,4 Information Systems Management Department, BINUS Graduate Program - Master of Information Systems \\ Bina Nusantara University, Jakarta, Indonesia, 11480. ${ }^{1}$ michael.shane@ binus.ac.id, ${ }^{2}$ lukman.wisnudrajat@binus.ac.id, \\ 33wang@binus.edu, ${ }^{4}$ emil.kaburuan@ binus.edu
}

\begin{abstract}
This paper presents a proposed Web-based gamification system for recruiting employees. The most important asset in a company is its employees. However, it is increasingly difficult for HR professionals to acquire and maintain the required talents. To solve this issue, organizations are starting to use gamification. Gamification is a design process where elements or mechanics in gaming are added to a non-game application or system. Compared to the standard recruitment, gamified recruitment has several advantages such as: 1) identify motivated candidates, 2) evaluate people without much experience more easily, 3) evaluate people who have diverse experience, and 4) engage the candidate. By using Marczewski's gamification framework, we provide a theory-based guide on how to implement gamification in employee recruitment using a simple gamification framework. Though this proposed idea has not yet been tested, we believe that this idea is feasible in real life application.
\end{abstract}

Key words : gamification, gamification framework, Marczewski, gamification design, human resources, recruitment

\section{INTRODUCTION}

The most important asset in a company is its employees [1]. According to an article published by Forbes, employees are more important to an organization's success than customers [2]. Therefore, organizations need to employ and maintain the right people to maximize the organization's chances for success [3]. However, it is increasingly difficult for HR professionals to acquire and maintain the required talents. To help mitigate this issue, technologically literate organizations are starting to digitize their human resources department [4], including the use of gamification.

The concept of gamification is based on and is linked to a variety of theories such as communication, human psychology, motivation, learning and development, behavioral economics, problem-solving, teamwork, decision making, and risk-taking. Well-designed gamification of real-world objectives can increase employees' performance and engagement by connecting with the employees' untapped player potential, which results in a win-win condition for both employees and organizations [5].

The goal of gamification in human resources (HR) is not about creating an immersive, video game-like experience for the employees. Rather, the goal is to help an organization achieve its objectives such as increasing employee engagement by using elements and mechanics found in video games. Moreover, the use of gamification may help HR in adding value to the organization and provide a new way for the organization to measure HR's contribution. Gamification in HR is first and foremost business-minded, and therefore it should focus on things that will support in achieving business objectives and goals. By using gamification, HR is encouraging employees to do more, and at the same time get better.

Game concepts and ideas can be utilized in HR in various manners. For instance, HR can use gamification to appeal, recruit, train, develop, engage, and retain employees. Apart from the examples listed previously, many ways are yet to be discovered in which gamification can be used in HR. The focus of this paper is using gamification in employee recruitment.

\section{LITERATURE REVIEW}

\subsection{Gamification}

Gamification is a design process where elements or mechanics in gaming are added to a non-game application or system [6]. Kevin Werbach (2013) of the University of Pennsylvania defines gamification as "the use of design techniques from games in a business context or some other non-game context" [7]. In layman's term, the concept of gamification can be described as follows: remodel daily routine and assignment - from employee training and 
recruiting to quality control and other activities - to be more game-like and interactive, eventually augmenting work experience to be more engaging, fulfilling, fun and productive. Werbach stresses that gamification is "more than just rewards and points" but about employees' engagement and motivation in a "playful way". This is with the end goal of connecting with the employees and coordinating them towards business goals. Brian Burke sees this as a means to drive the employees to accomplish "extraordinary things" [8]. There is a misconception that gamification is the same as "serious games". A "serious game" is a game that is created for non-recreation purposes (for instance, a learning game software) while on the contrary "gamification" is the use of game elements and mechanics in a non-game context [5]. Gamification concepts have been used for many years in the business. For example, gamification concepts have been used as early as the 1900s with shops offering free gifts or products with multiple product purchases. The idea of using gamification began to gain popularity around 2009 and 2010, where gamification is becoming an increasingly important part of the modern business environment. Ty McCormick (2013) described gamification as "the hottest business buzz-word" [9]. In addition, according to MarketsandMarkets, the gamification market is forecasted to be worth $\$ 11.10$ billion USD in 2020 [10].

However, Heather Clancy (2014) hinted that "looks like that whole 'gamification' thing is over" [11]. Similar to cited notions of potential change management failure rates more broadly, Burke is of the opinion that "Gamification has tremendous potential, but most businesses are not getting it right at the moment," which is likely why Gartner placed Gamification in their most recent Hype Cycle of Emerging Technologies in 2014 in the "trough of disillusionment" [8]. There is evidence that gamification principles are used in areas as diverse as shopping, education, health and well-being. Examples include SAP uses games to teach its staff about sustainability, Unilever uses games to train their employees, Hays uses them to hire recruiters and the Khan Academy uses them for online training. The Aberdeen Group (2013) stated that organizations that employ gamification see better results, including efficiency, engagement and retention [12].

\subsection{Recruitment}

Recruitment of employee is defined as “an employer's action that aims to 1) bring a job opening to the attention of potential job applicants who do not currently work for an agency, 2) influence whether they apply for a job, 3) affect whether they remain interested until a job offer is made and 4) influence whether a job offer is accepted" [13]. Recruitment can be conceptualized as an attitude training / change process involving individuals who develop an idea of what it would be like to work for an organization. In this paper we will address the gamification features that allow it to be used as a persuasive design and advocate for its potential to change attitudes towards organizations and/or industries. In the hiring sense, we suggest that gamification is basically an attempt to change the mindset of potential applicants towards the company by engaging them more directly in the recruitment process. Marriott Hotels, for example, has developed a game that simulates the duties of hotel managers in order to introduce potential applicants to the challenges and opportunities of managing a hotel. In doing so, they hope to change the attitudes of potential candidates towards the hotel industry, and especially Marriott [14]. The psychological literature provides ample theoretical guidance for understanding how and when gamification, such as that used by Marriott, will affect employee attitudes and thus the attraction to an organization / industry.

\section{METHODOLOGY}

In this research, the authors use Marczewski's Gamification Framework as the framework of choice. This framework was chosen due to its simplicity compared to other gamification frameworks, thus making it easier to create and implement. Albeit its simplicity, the authors believe that this framework is suitable for gamifying recruitment. Another reason this framework was chosen is that this framework divides the player into four intrinsically motivated types, which are Socializer, Free Spirit, Achiever, and Philanthropist; each with their own unique traits. By identifying the traits of our target user, we can create a design that suits the target user. This will undoubtedly increase the gamified system's probability of success.

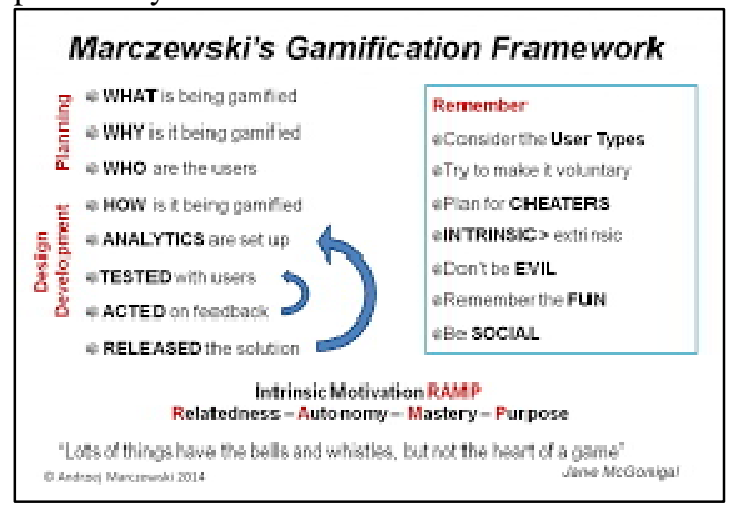

Figure 1: Marczewski’s Gamification Framework

At the planning stage, there are 4 things that underline the gamification design [15]:

1. What is being gamified (What will be the gamified system?)

2. Why is it being gamified (Why will it be a gamified system?)

3. Who is the user (Who is the user of gamified system?)

4. How it is being gamified (How to make a gamified system?) 
The planning section will determine the boundaries of the framework that is designed and determine the objectives of the framework itself. The next stage is the design stage, a stage where motivation, feedback \& game mechanics, user journey, and engagement/feedback loops will be determined. However, this research only focuses on 2 components, namely motivation and feedback \& game mechanics. For the player type, we will focus on the Achiever type. Achievers are motivated by mastery. They are characterized by their desire to gain knowledge, learn new skills, self-improvement, and overcoming challenges presented to them [16]. These are all traits that are desired by employers, regardless of company type.

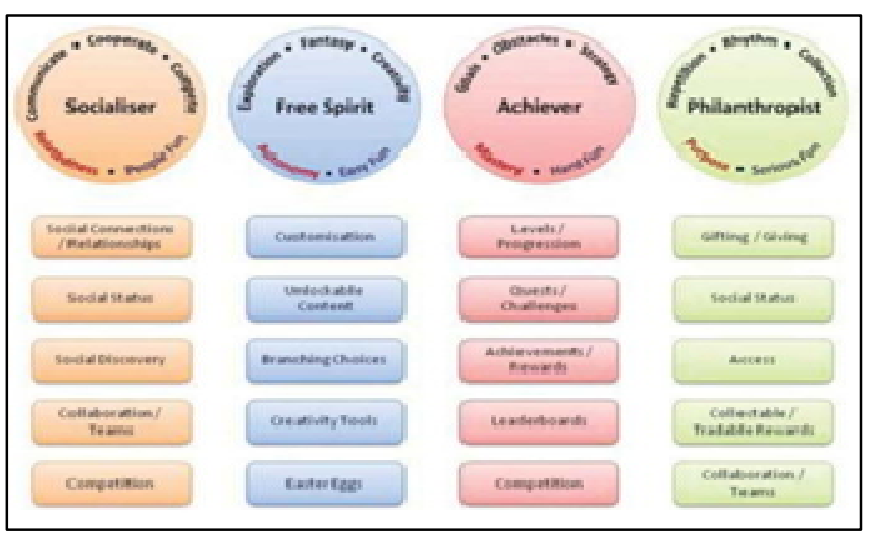

Figure 2: Player types and suitable game mechanics for each player type

The Achiever player type is also driven by status as a representation of achievement. They need a system that can enrich and lead to mastery. An award can be given for those who have achievements and have completed challenges. Here are the game mechanics for Achiever type players:

1. Levels / Progression is a means to show the progress of a player. Levels can be shown in the form of a progress bar, icon, or metaphor (bronze, silver, gold, and platinum) [17].

2. Quests / Challenges are used by the system to provide challenges and provide guidance to players about what can be done to be able to continue to a higher level [17].

3. Achievements / Rewards is a gift, tangible or intangible, presented after the occurrence of an action (i.e. behavior) with the intention of causing the behavior to occur again [18].

4. Leaderboards aim to make simple comparisons. Most people don't need any explanation when they face the leaderboard. By default, an ordered list appears with a score next to each name, and we understand that we see a ranking system [17].

5. Competition allows users to challenge each other to get high scores on several activities. After everyone has done the activity, the user with the highest score wins the prize. Usually used for multi-player games [18].

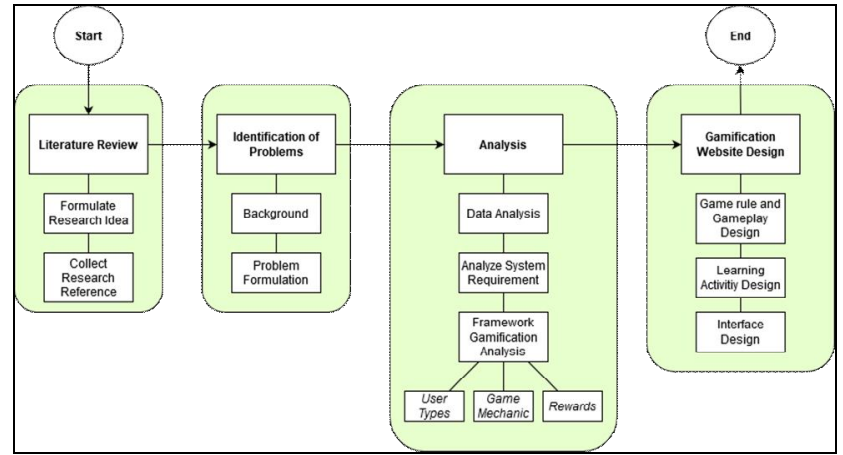

Figure 3: Gamified system research flow

After the design is finalized a trial will be carried out to test the success of the gamified system design, user testing, and an evaluation of the gamified system in order to collect feedback. Once the feedback data is collected and analyzed, we can see how well the gamified system works and identify which part of the system, if any, that needs to be modified or improved.

\section{DISCUSSION}

\subsection{Gamification Framework Analysis}

The gamification framework used in employee recruitment is Marczewski's Gamification Framework. Based on Figure 1, the analysis of the planning and design of a web-based gamified system is summarized in Table 1.

Table 1: Attributes of Cleveland dataset

\begin{tabular}{|c|c|c|}
\hline No. & Stage & Description \\
\hline \multirow[t]{4}{*}{1} & Planning & \\
\hline & $\begin{array}{l}1.1 \text { What is } \\
\text { being gamified? }\end{array}$ & $\begin{array}{l}\text { In this study, the proposed } \\
\text { recruitment system that will be } \\
\text { designed in the form of a web } \\
\text { app. }\end{array}$ \\
\hline & $\begin{array}{l}1.2 \text { Why is it } \\
\text { being gamified? }\end{array}$ & $\begin{array}{l}\text { Compared to the standard } \\
\text { recruitment, a gamified } \\
\text { recruitment has several } \\
\text { advantages such as: 1) identify } \\
\text { motivated candidates, 2) } \\
\text { evaluate people without much } \\
\text { experience more easily, 3) } \\
\text { evaluate people who have } \\
\text { diverse experience, and 4) } \\
\text { engage the candidate [19]. }\end{array}$ \\
\hline & $\begin{array}{l}1.3 \text { Who is the } \\
\text { user? }\end{array}$ & $\begin{array}{l}\text { The users of this gamified } \\
\text { system are job applicants. }\end{array}$ \\
\hline \multirow[t]{2}{*}{2.} & Design & \\
\hline & $\begin{array}{l}2.1 \text { How is it } \\
\text { being gamified? }\end{array}$ & $\begin{array}{l}\text { The design of this web will use } \\
\text { only } 2 \text { elements from the } 4 \\
\text { design elements in the } \\
\text { Marczewski's Gamification } \\
\text { Framework, namely Motivation } \\
\text { and Feedback \& Game } \\
\text { Mechanics. Motivation is used } \\
\text { to determine User Types on the } \\
\text { gamified system. Whereas } \\
\text { Feedback \& Game Mechanics }\end{array}$ \\
\hline
\end{tabular}




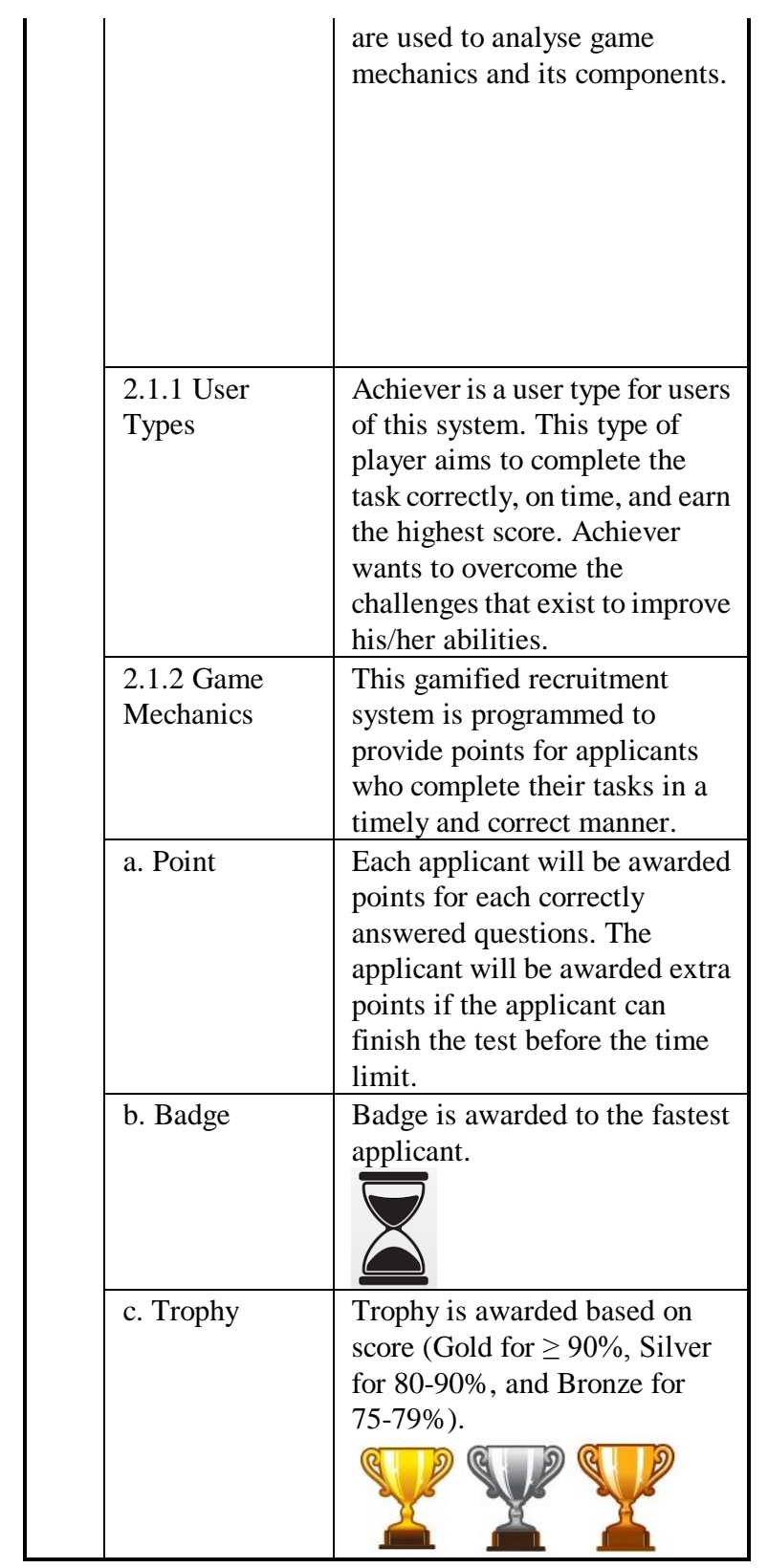

\subsection{Game Rules}

A game has a system where players are involved in an artificial conflict defined by rules that produce something that can be measured. Rules in the game are important because rules define the mechanism of the game, but not the game itself. The purpose of rules is to determine the candidate's score, badge, and trophy

\subsection{Gameplay}

After designing the game rules, the next thing to set up is gameplay design. Gameplay is a system of running the game. The player of this gamified system is the candidates. The gameplay flow is shown in Figure 3.

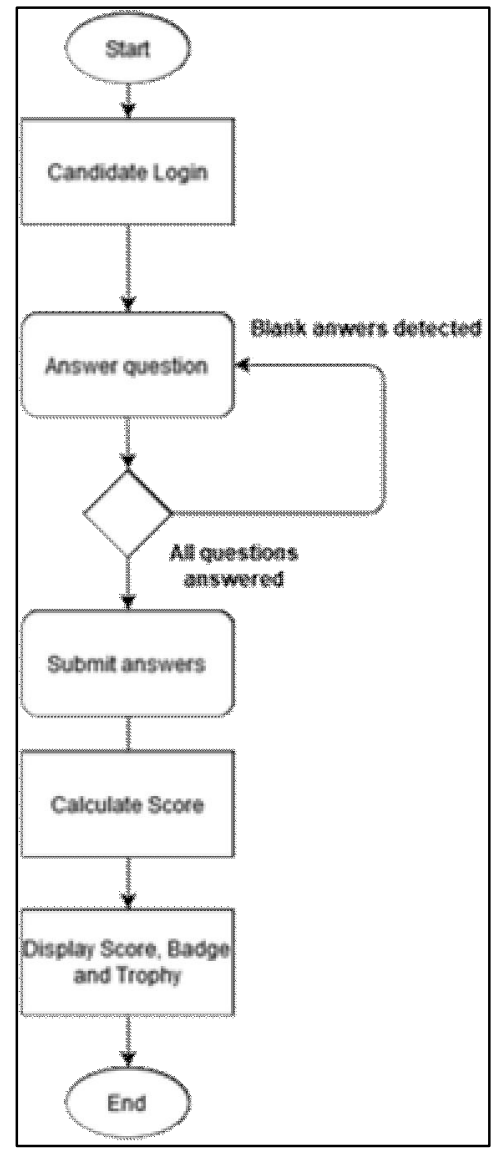

Figure 4: Gameplay flow

\subsection{User Interface Prototype}

In this section, we will show the user interface (UI) prototype of the proposed system based on the gameplay flow diagram shown in the previous section.

The user starts at the login page, where he/she will input the Candidate ID number and agree to the terms and conditions of the test.

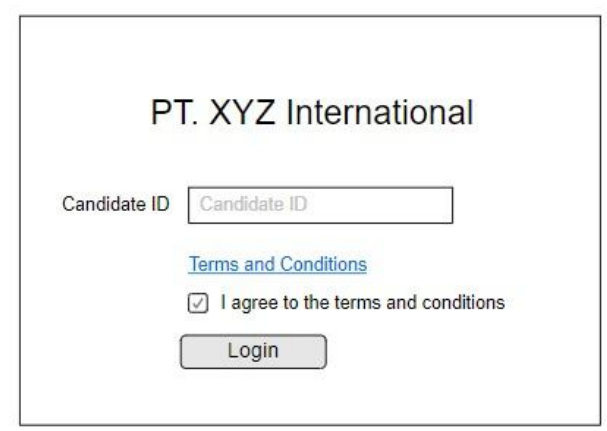

Figure 5: Login screen

Once the user is logged in, the page will show the test questions and the submit button can only be clicked once all questions are answered. If the user failed to finish the test before the allotted time, the system will automatically submit the answers. 


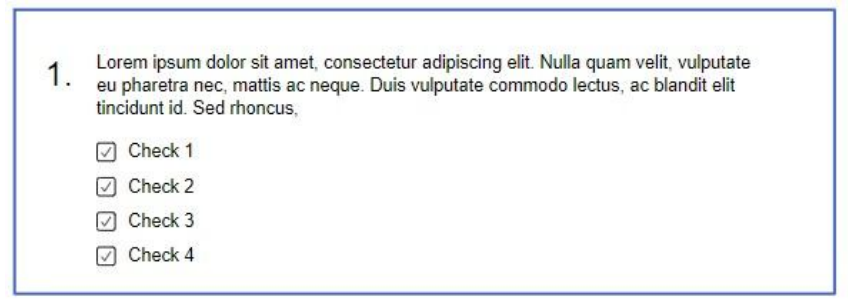

2. Lorem ipsum dolor sit amet, consectetur adipiscing elit. Nulla quam velit, vulputate eu pharetra nec, mattis ac neque. Duis vulputate commodo lectus, ac blandit elit tincidunt id. Sed rhoncus,

- Pizza

○ Sushi

- Steak

○ Pasta that organizations are slapping carelessly on point systems, leaderboards, and game graphics to "gamify" their processes. This paper attempts to provide a theory-based guide on how to implement gamification in employee recruitment using a simple gamification framework.

\section{REFERENCES}

[1] N. Nawaz, "AI is transforming recruitment effectiveness in CMMI level companies," Int. J. Adv. Trends Comput. Sci. Eng., vol. 8, 2019, doi: 10.30534/ijatcse/2019/56862019.

[2] L. Ryan, "Five Reasons Employees Are More Important Than Customers," Forbes, 2016. [Online]. Available:

https://www.forbes.com/sites/lizryan/2016/11/01/fiv e-reasons-employees-are-more-important-than-custo mers/\#5093d2e7db3e.

[3] H. Mobaideen, S. Allahawiah, and K. Alomari, "The Impact of Human Resources Information Systems on Human Resources Selection and Recruitment Strategy: An applied study on Arab Potash Company in the Hashemite Kingdom of Jordan," Int. J. Adv. Trends Comput. Sci. Eng., vol. 8, pp. 2475-2484, 2019, doi: 10.30534/ijatcse/2019/93852019.

[4] C. Jimenez, "Intelligent Shortlisting Process for Job Applicants Using Fuzzy Logic-Based Profiling," Int. J. Adv. Trends Comput. Sci. Eng., vol. 8, pp. 567-572, 2019, doi: 10.30534/ijatcse/2019/36832019.

[5] P. Simpson and P. Jenkins, "Gamification and Human Resources: an overview," Brighton, 2015.

[6] S. Deterding, D. Dixon, R. Khaled, and L. Nacke, "From Game Design Elements to Gamefulness: Defining 'Gamification,", in Proceedings of the 15th International Academic MindTrek Conference: Envisioning Future Media Environments, 2011, pp. 9-15, doi: 10.1145/2181037.2181040.

[7] K. Werbach, "Exclusive Interview: Kevin Werbach, Gamification MOOC by StudentAdvisor.com," 2013. [Online]. Available: http://www.youtube.com/watch?v=7F19VN48uDo.

[8] B. Brian, "Gartner: Gamification," Gartner, 2014. [Online].

Available: http://www.gartner.com/technology/research/gamifi cation/.

[9] T. McCormick, “Anthropology of an idea: gamification: why everybody, from corporate titans to terrorists, wants to make life more like a game," Foreign Policy, pp. 26-27, 2013.

[10] MarketsandMarkets, "Gamification Market by Solution (Consumer driven and Enterprise driven), Applications (Sales and Marketing), Deployment Type (On-Premises and Cloud), User Type (Large Enterprise, SMBs), Industry and Region - Global Forecast to 2020," 
MarketsandMarkets, 2016. [Online]. Available: https://www.marketsandmarkets.com/Market-Report s/gamification-market-991.html.

[11] H. Clancy, "Looks like that whole 'gamification' thing is over," Fortune, 2014. [Online]. Available: https://fortune.com/2014/06/06/looks-like-that-whol e-gamification-thing-is-over/.

[12] Aberdeen Group, "Is it time to gamify your onboarding program?," 2013.

[13] A. E. Barber, Recruiting Employees: Individual and Organizational Perspectives. 1998.

[14] J. Lopez, "Marriott Makes Facebook Game for Recruitment," Gamification Co., 2011. [Online]. Available:

http://www.gamification.co/2011/06/24/Marriot\%0 Att-makes-facebook-game-for-recruitment/,.

[15] A. Marczewski, "A Simple Gamification Framework / Cheat Sheet - Andrzej's Blog," Gamified UK, 2013. .

[16] A. Marczewski, "User Types HEXAD," 2015, pp. 65-80.

[17] G. Zichermann and C. Cunningham, Gamification By Design. 2011.

[18] Bunchball Inc., "Gamification 101: An Introduction to the Use of Game Dynamics to Influence Behavior," Bunchball white Pap., 2010, doi: 10.1016/j.compedu.2012.12.020.

[19] N. Bika, "Gamification in recruiting: How and why to give it a shot," Workable. [Online]. Available:

https://resources.workable.com/stories-and-insights/ gamification-in-recruiting-effectiveness. 